\title{
Numerical Simulation of the Hydraulic Performances and Flow Pattern of Swallow-Tailed Flip Bucket
}

\author{
Lifang Zhang, ${ }^{1}$ Jianmin Zhang $\mathbb{D}^{1},{ }^{1}$ Yakun Guo, ${ }^{2}$ and Yong Peng $\mathbb{D}^{1}$ \\ ${ }^{1}$ State Key Laboratory of Hydraulics and Mountain River Engineering, Sichuan University, Chengdu 610065, China \\ ${ }^{2}$ Faculty of Engineering \& Informatics, University of Bradford, BD7 1DP, Bradford, UK \\ Correspondence should be addressed to Yong Peng; pengyongscu@foxmail.com
}

Received 5 December 2019; Revised 1 April 2020; Accepted 20 April 2020; Published 14 May 2020

Academic Editor: Efstratios Tzirtzilakis

Copyright ( 2020 Lifang Zhang et al. This is an open access article distributed under the Creative Commons Attribution License, which permits unrestricted use, distribution, and reproduction in any medium, provided the original work is properly cited.

In this study, the evolution process of the swallow-tailed flip bucket water nappe entering into the plunge pool is simulated by using the standard $k-\varepsilon$ turbulence model and the volume-of-fluid method. The effects of the upstream opening width ratio and downstream bucket angle on the flow pattern, the unit discharge distribution, and the impact pressure distribution are studied. Based on the numerical results, the inner and outer jet trajectories are proposed by using the data. Results show that the longitudinal stretching length decreases with the increase of the upstream opening width ratio and increases with the increase of the downstream bucket angle. The water nappe enters the plunge pool in a long strip shape. Thus, the unit discharge distribution of water nappe entry is consistent with the pressure distribution at the plunge pool bottom. The upstream opening width ratio and downstream bucket angle should be chosen as their intermediate values in order to have a uniform discharge distribution and to reduce the pressure peak at the plunge pool floor, which is effectively to avoid instability and destruction of plunge pool floor.

\section{Introduction}

The ski-jump energy dissipation is usually adopted in the high dam project $[1,2]$. The free jet discharging from traditional flip buckets entrains air and becomes air-water twophase flow before entering the plunge pool downstream [3]. This two-phase jet will cause energy dissipation through shearing and disturbance [4]. Due to the practical engineering importance, extensive studies have been carried out to investigate how to distribute the water nappe evenly in the downstream channel in order to reduce the scouring of riverbed $[5,6]$. A new type of leak-floor flip bucket was developed [7] to handle hydraulic engineering with relatively narrow downstream channels. On the basis of conventional continuous flip bucket, the floor is partially hollow and looks like a swallowtail. For this reason, it is named as swallowtailed flip bucket. Qian [8] conducted laboratory experiments and numerical simulations to investigate the effects of upstream angle, opening ratio, and antiarc radius of the swallow-tailed flip bucket on water entry length but did not propose a formula to calculate the jet trajectory. Deng et al.
[7] compared and analyzed the formation mechanism and characteristics of the water jet between the swallow-tailed bucket and slit-type flip bucket. Mao et al. [9] carried out experiments and found that the symmetric swallow-tailed flip bucket could effectively solve the scouring problem of the riverbed of Huangdeng Hydropower Station, China. Wang et al. [10] conducted laboratory physical experiments and concluded that the symmetric swallow-tailed array flip buckets can fully stretch the water jet in the limited space to protect the bank from erosion. Li et al. [11] applied FLOW$3 \mathrm{D}$ software with a renormalization group turbulence model to the Shiziya reservoir in China. With adjustments of the angles of the left and right walls, the width and jet angle of the dovetail-shaped bucket (different from swallow-tailed flip bucket) are optimized to meet the flood safety requirements. Karami Moghadam et al. [12] investigated the influence of the variation in the angle of pool impact plate, plunging depth, and discharge to the dynamic pressure caused by ski-jump buckets. The model scale and prototype flow discharge of the experiments carried out by the above mentioned authors are listed in Table 1. 
TABLE 1: Summary of previous physical model tests.

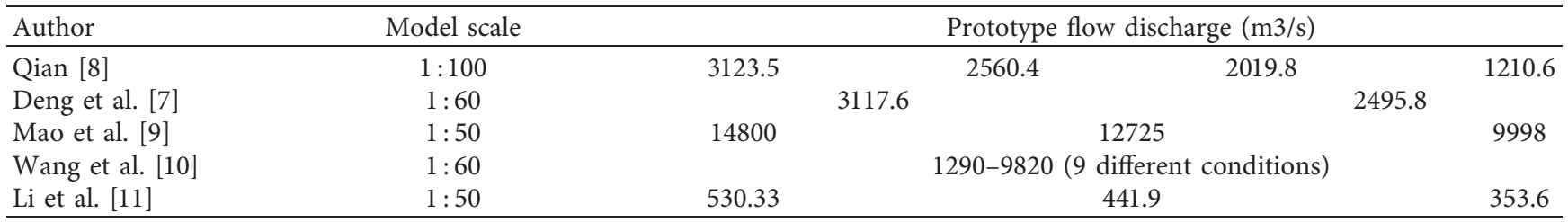

Most studies in literature have primarily focused on the effect of body shape parameters on jet trajectory distance and scour characteristics. Few studies have investigated the trajectory and unit discharge distribution of the water nappe. A numerical simulation method can track the free surface and easily obtain the trajectory as well as the discharge distribution at different elevation sections. In this paper, numerical simulations will be carried out for three upstream opening widths $(4 \mathrm{~m}, 6 \mathrm{~m}, 8 \mathrm{~m})$ and four downstream bucket angles $\left(25^{\circ}, 30^{\circ}, 35^{\circ}, 40^{\circ}\right)$ of the gap to study the effects of the shape parameters on the flow pattern, the discharge distribution, and the pressure distribution. The modified formulas about the inner and outer trajectories are proposed by utilizing all the data points of the jet trajectory. The results can be used as a reference for designers to select appropriate shape parameters to make the distribution of water nappe more uniform and reduce the risk of damage to the plunge pool.

\section{Numerical Model and Validation}

2.1. Computational Model Layout. According to the general layout of a water conservancy project, the three-dimensional (3D) model consisting of spillway and plunge pool is established, which is shown in Figure $1(\mathrm{a})$. The $x$-axis is perpendicular to the dam axis, pointing from upstream to downstream and ranging from $90 \mathrm{~m}$ to $512 \mathrm{~m}$. The $y$-axis points from the right bank to the left bank, ranging from $-20 \mathrm{~m}$ to $20 \mathrm{~m}$. $Y=0 \mathrm{~m}$ is the central axis of the spillway dam section. The $z$-axis ranges from $0 \mathrm{~m}$ to $89 \mathrm{~m}$. The plunge pool is in cuboid shape, and the elevation of the bottom plate is $450 \mathrm{~m}$ in practical engineering. The geometric parameters of the swallow-tailed flip bucket are shown in Figure 1(b). The parameters are as follows: $B$, total width of the bucket $(14 \mathrm{~m})$; $B_{1}$, upstream opening width of the gap; $B_{2}$, downstream opening width of the gap $(10 \mathrm{~m}) ; \theta_{1}$, upstream bucket angle of the gap $\left(15^{\circ}\right) ; \theta_{2}$, downstream bucket angle of the gap; $R$, the antiarc radius of the bucket $(80 \mathrm{~m})$. The physical model test and numerical simulation are carried out with shape parameters $B_{1}=6 \mathrm{~m}$ and $\theta_{2}=35^{\circ}$ for validation. The validated model is then applied to simulate the five cases, as shown in Table 2.

2.2. Governing Equations and Solution Methods. The standard $k-\varepsilon$ turbulence model has been successfully applied to study the ski-jump energy dissipation in practical engineering [13-15]. Considering its computational efficiency, the standard $k-\varepsilon$ turbulence model [16] and volume-of-fluid (VOF) technique for tracking the free surface [17] are adopted in the present study. The governing equations are as follows:

Continuity equation:

$$
\frac{\partial \rho}{\partial t}+\frac{\partial\left(\rho u_{i}\right)}{\partial x_{i}}=0
$$

Momentum equation:

$\frac{\partial\left(\rho u_{i}\right)}{\partial t}+\frac{\partial\left(\rho u_{i} u_{j}\right)}{\partial x_{j}}=-\frac{\partial p}{\partial x_{i}}+\frac{\partial}{\partial x_{j}}\left[\left(\mu+\mu_{t}\right)\left(\frac{\partial u_{i}}{\partial x_{j}}+\frac{\partial u_{j}}{\partial x_{i}}\right)\right]$.

$k$ (turbulent kinetic energy) equation:

$$
\frac{\partial(\rho k)}{\partial t}+\frac{\partial\left(\rho u_{i} k\right)}{\partial x_{i}}=\frac{\partial}{\partial x_{j}}\left[\left(\mu+\frac{\mu_{t}}{\sigma_{k}}\right) \frac{\partial k}{\partial x_{j}}\right]+G_{k}-\rho \varepsilon
$$

$\mathcal{E}$ (dissipation rate of turbulent kinetic energy) equation:

$$
\frac{\partial(\rho \varepsilon)}{\partial t}+\frac{\partial\left(\rho u_{i} \varepsilon\right)}{\partial x_{i}}=\frac{\partial}{\partial x_{i}}\left[\left(\mu+\frac{\mu_{t}}{\sigma_{\varepsilon}}\right) \frac{\partial \varepsilon}{\partial x_{i}}\right]+C_{1 \varepsilon} \frac{\varepsilon}{k} G_{k}-C_{2 \varepsilon} \rho \frac{\varepsilon^{2}}{k},
$$

with

$$
\begin{aligned}
\mu_{t} & =\rho C_{\mu} \frac{k^{2}}{\varepsilon} \\
G_{k} & =\mu_{t}\left(\frac{\partial u_{i}}{\partial x_{j}}+\frac{\partial u_{j}}{\partial x_{i}}\right) \frac{\partial u_{i}}{\partial x_{j}}
\end{aligned}
$$

where $t$ is time; $u_{\mathrm{i}}$ is the average velocity component in the $i$ th direction; $p$ is pressure; $\rho$ and $\mu$ are the average density and dynamic viscosity, respectively. $G_{k}$ is the generation of turbulence kinetic energy due to the mean velocity gradients. $\mu_{t}$ is the turbulent viscosity which can be deduced for the turbulence intensity $k$ and energy dissipation rate $\varepsilon$. $C_{\mu}=0.09, \sigma_{k}=1.0, \sigma_{\varepsilon}=1.3, C_{1 \varepsilon}=1.44$, and $C_{2 \varepsilon}=1.92$.

The volume-of-fluid method is used to track the free surface. For diversified hydraulic issues, the VOF model is often applied to simulate free-surface flows including freefalling jets. $\rho$ and $\mu$ in the abovementioned equations are given by equations (6) and (7). equation (8) is the continuity equation for the volume fraction of water.

$$
\begin{aligned}
\rho & =\alpha_{w} \rho_{w}+\left(1-\alpha_{w}\right) \rho_{a}, \\
\mu & =\alpha_{w} \mu_{w}+\left(1-\alpha_{w}\right) \mu_{a}, \\
\frac{\partial \alpha_{w}}{\partial t}+\frac{\partial \alpha_{w} u_{i}}{\partial x_{i}} & =0
\end{aligned}
$$




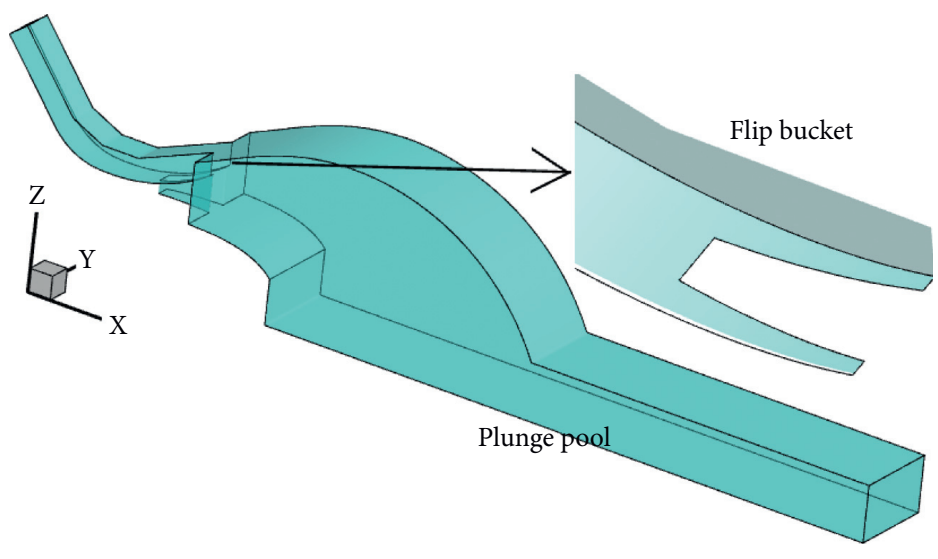

(a)

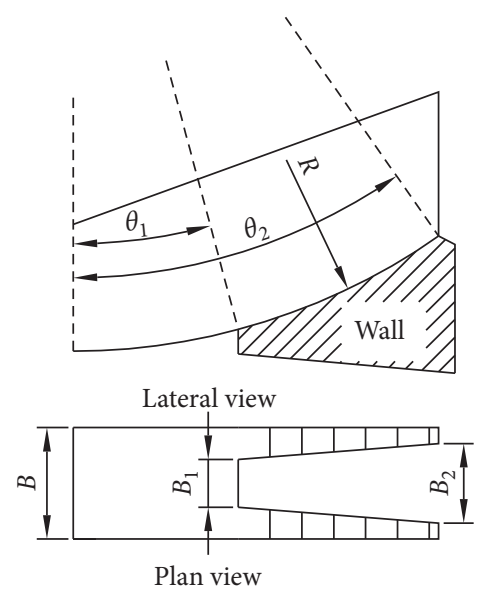

(b)

FIgURE 1: Layout of the numerical model: (a) general layout; (b) shape parameters of the swallow-tailed flip bucket.

where $\alpha_{w}$ is the volume fraction of water; $\rho_{w}$ and $\rho_{a}$ are the density of water and air, respectively; $\mu_{w}$ and $\mu_{a}$ are the viscosities of water and air, respectively.

The governing equations are discretized based on the finite volume method using the Pressure-Implicit with Splitting of Operators (PISO) algorithm for the pressurevelocity coupling. The volume fraction is discretized by GeoReconstruct. The second-order upwind scheme is used for the momentum, the turbulent kinetic energy, and the dissipation rate.

\subsection{Boundary Conditions. The boundary conditions are as} follows:

(1) Inlet boundary: the inlet is divided into two parts, which are velocity-inlet boundary for water phase and pressure-inlet boundary for air phase, respectively. The unit discharge of the spillway surface hole is set as $87.38 \mathrm{~m}^{2} / \mathrm{s}$, and the inlet water depth is $2.869 \mathrm{~m}$ and the velocity is $30.46 \mathrm{~m} / \mathrm{s}$;

(2) Outlet boundary: pressure-outlet; utilizing user-defined function file to control the downstream water depth fixed at $19.94 \mathrm{~m}$;
(3) Wall boundary: no-slip velocity boundary condition; the near-wall regions of the flow were analyzed using the method of standard wall function;

2.4. Grid Testing. The mesh of the numerical model is configured as a structural grid. In order to reduce the virtual diffusion of numerical simulation and improve computational efficiency, the direction of grid division should be consistent with that of the trajectory of water nappe. The flip bucket segment is refined to get a better shape of water nappe. Global maximum grid size is $2 \mathrm{~m}$, the maximum grid size of the inlet along the $z$-axis is $0.5 \mathrm{~m}$, and the transverse grid size of the flip bucket section, from $Y=-7 \mathrm{~m}$ to $Y=7 \mathrm{~m}$, is set as $0.1 \mathrm{~m}, 0.2 \mathrm{~m}$, and $0.4 \mathrm{~m}$, respectively. The total number of the three grids used in the grid test is 1.29 million (grid 1), 0.78 million (grid 2), and 0.39 million (grid 3), respectively.

In order to verify the accuracy of the numerical model, the grid convergence index (GCI) [18] is used to estimate the uncertainty with different grid sizes. The GCI is given by

$$
\begin{aligned}
\mathrm{GCI}_{\text {fine }}^{21} & =\frac{1.25\left|\left(\phi_{1}-\phi_{2}\right) / \phi_{1}\right|}{\left(h_{2} / h_{1}\right)^{p}-1}, \\
h & =\left[\frac{1}{N} \sum_{i=1}^{N}\left(\Delta V_{i}\right)\right]^{1 / 3}, \\
p & =\frac{1}{\ln \left(h_{2} / h_{1}\right)}|\ln |\left(\phi_{3}-\phi_{2}\right) /\left(\phi_{2}-\phi_{1}\right)|+\ln | \frac{\left(h_{2} / h_{1}\right)^{p}-1 \cdot \operatorname{sgn}\left[\left(\phi_{3}-\phi_{2}\right) /\left(\phi_{2}-\phi_{1}\right)\right]}{\left(h_{3} / h_{2}\right)^{p}-1 \cdot \operatorname{sgn}\left[\left(\phi_{3}-\phi_{2}\right) /\left(\phi_{2}-\phi_{1}\right)\right]}||
\end{aligned}
$$

where $\phi_{k}$ is the solution on the $k$ th grid and $h_{k}$ is the average grid size on the $k$ th grid and $h_{1}<h_{2}<h_{3} . \Delta V_{i}$ is the volume of the $i$ th cell and $N$ is the total number of cells used for the computations. 
TABLE 2: Designed cases of the swallow-tailed flip bucket.

\begin{tabular}{lccc}
\hline Case & $B_{1}(\mathrm{~m})$ & $B_{1} / B$ & $\theta_{2}$ \\
\hline$\# 1$ & 6 & 0.429 & $35^{\circ}$ \\
$\# 2$ & 8 & 0.571 & $35^{\circ}$ \\
$\# 3$ & 4 & 0.286 & $35^{\circ}$ \\
$\# 4$ & 6 & 0.429 & $40^{\circ}$ \\
$\# 5$ & 6 & 0.429 & $30^{\circ}$ \\
$\# 6$ & 6 & 0.429 & $25^{\circ}$ \\
\hline
\end{tabular}

Figure 2 shows the uncertainty in the pressure along the centerline of the spillway floor, which is written in a dimensionless form as $P / P \max$. GCI values are plotted in the form of error bars. Based on the grid convergence index, the maximum discretization uncertainty is $7.9 \%$ at $X=156 \mathrm{~m}$, and the uncertainty was small in most locations. Considering the computational accuracy and time, the number of grids is set as 0.78 million.

2.5. Model Validation. In order to verify the accuracy and reliability of the numerical simulations, physical model experiments are carried out at the State Key Laboratory of Hydraulics and Mountain River Engineering, Sichuan University, China. The prototype is the spillway of a project located on the midstream of the Yellow River. The physical model consists of an upper water tank, WES (Waterways Experimental Station) weir, flip bucket segment, plunge pool, measuring weir, and an underground reservoir. The scale of the normal model is 1:60 based on the Froude number similarity. The WES weir and the flip bucket are shown in Figure 3. The hydraulic conditions of the experiment are shown in Table 3; the upstream water level is $2.925 \mathrm{~m}$; the downstream water level is $0.332 \mathrm{~m}$; the designed flood discharge is $43.87 \mathrm{~L} / \mathrm{s}$. Six measurement points are distributed along the centerline of the flip bucket segment to record water depth and pressure. The timeaveraged pressure is measured using a piezometric tube. The water nappe is captured by a camera. The high-speed camera is fixed at 1 meter from the flume lateral wall and calibrated by the measuring tapes on the flume lateral wall to accurately extract the inner and outer trajectories of water nappe.

Figure 4(a) shows the comparison between the simulated and measured water surface profiles at sidewall. It can be seen that the calculated water surface profile agrees well with the experimental data. Figure 4(b) shows the comparison of the simulated and measured pressure on the ogee section along the central axis. Although the maximum deviation is $38 \%$ at $X=100 \mathrm{~m}$ between the experimentally measured and simulated data, in general, the simulation agrees well with the measurements. The pressure increases sharply at the ogee section and then decreases with the increase of the elevation of the spillway bottom plate and eventually approaches zero at the exit.

Figure 5 shows the numerical and experimental flow patterns of water nappe. It can be seen that the water nappe entrains air into the water jet during the trajectory and becomes well-aerated as well as is longitudinally stretched.

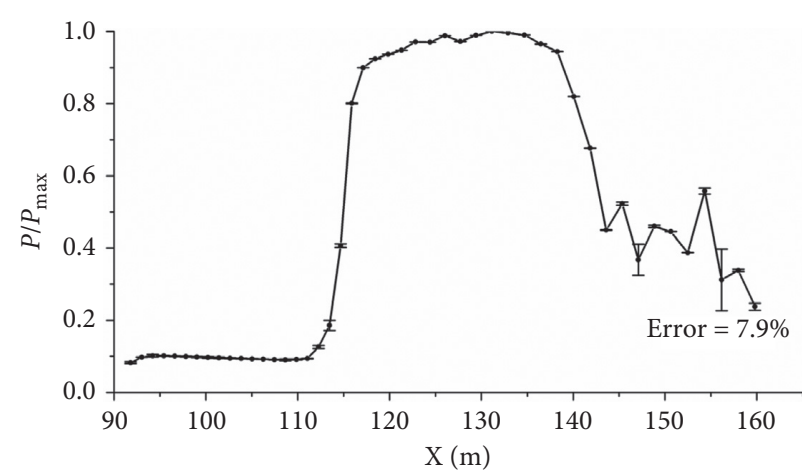

FIGURE 2: Fine-grid solution with discretization error bars computed using the GCI.

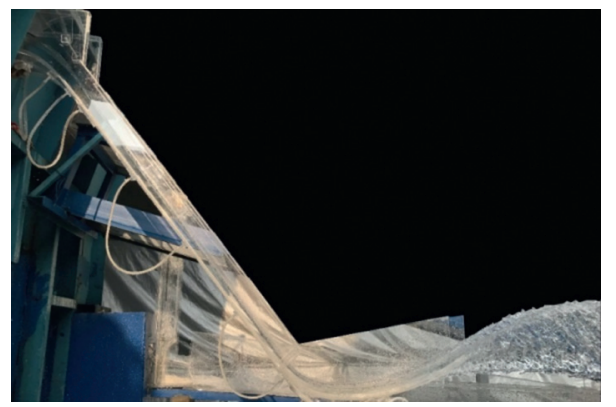

FIgURE 3: Layout of the WES weir and the flip bucket.

Table 4 compares the experimental and numerical values of the trajectory lengths. Simulation result for water phase volume fraction is chosen as 0.5 . The envelope of simulated water nappe is slightly larger than the experiment's while the maximum relative error is $5.62 \%$. The error may be ascribed to the following: on one hand, well-aerated upper portion of the water nappe will lead to errors in the experimental measurement; on the other hand, the scale effect always exists in the physical model test. Overall, the simulation agrees well with the experiment.

\section{Numerical Results and Analysis}

The flow pattern of the swallow-tailed flip bucket is different from that of the traditional bucket, as shown in Figure 6. The water in the middle ejects out and falls from the gap area firstly. Due to the widening of the gap, a small part of water on both sides of the bottom plate takes off at different angles, and the water surface is concave. Meanwhile, the water surface profile resembles "Y-type" in the cross-section. After leaving the bucket, water on both sides of the bottom plate contract to the central axis due to the pressure difference. When two jets collide and merge into one, the water surface profile resembles "I-type" in the cross-section, forming a longitudinal stretch sheet water nappe [7]. The formation of transverse velocity accounts for the above phenomenon, which is shown in Figure 6(b). Due to the existence of leak floor, there is pressure difference inside the water flow, resulting in the formation of transverse velocity up to $3 \mathrm{~m} / \mathrm{s}$. 
TABLE 3: Hydraulic conditions of the experiment.

\begin{tabular}{lccc}
\hline Model scale & Upstream water level $(\mathrm{m})$ & Downstream water level $(\mathrm{m})$ & Total discharge $(\mathrm{L} / \mathrm{s})$ \\
\hline $1: 60$ & 2.925 & 0.332 & 43.87 \\
\hline
\end{tabular}

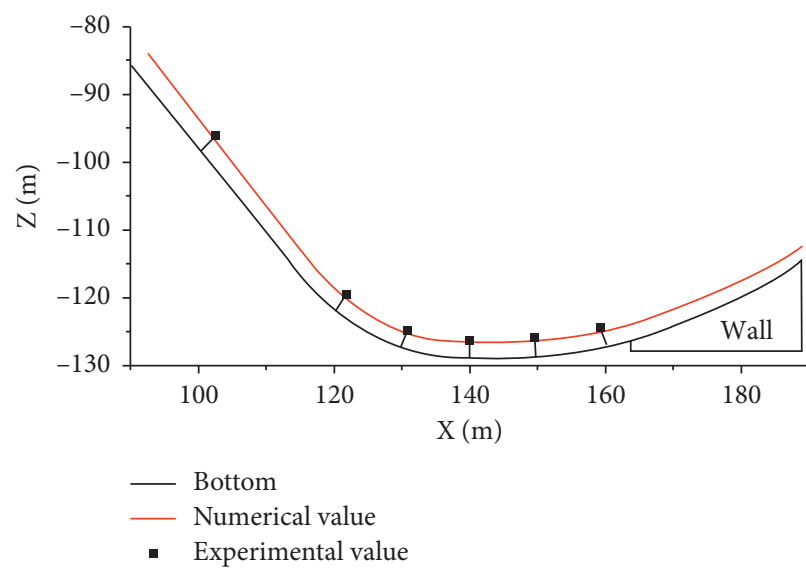

(a)

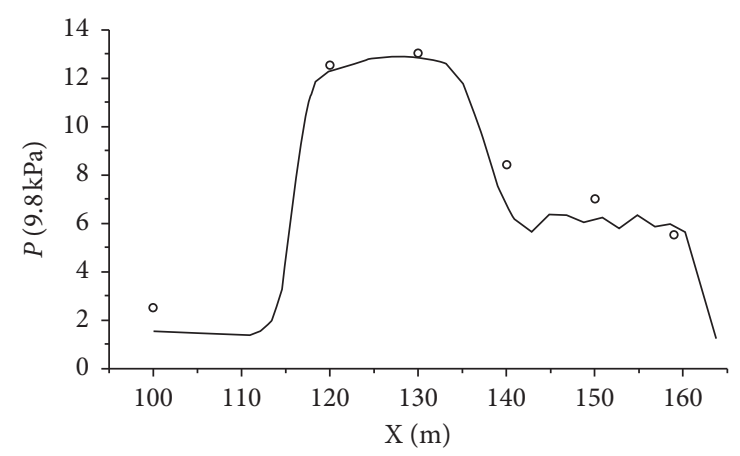

- Experimental value

- Numerical value

Figure 4: Comparison of numerical and experimental values: (a) water surface profile; (b) pressure along the centerline.

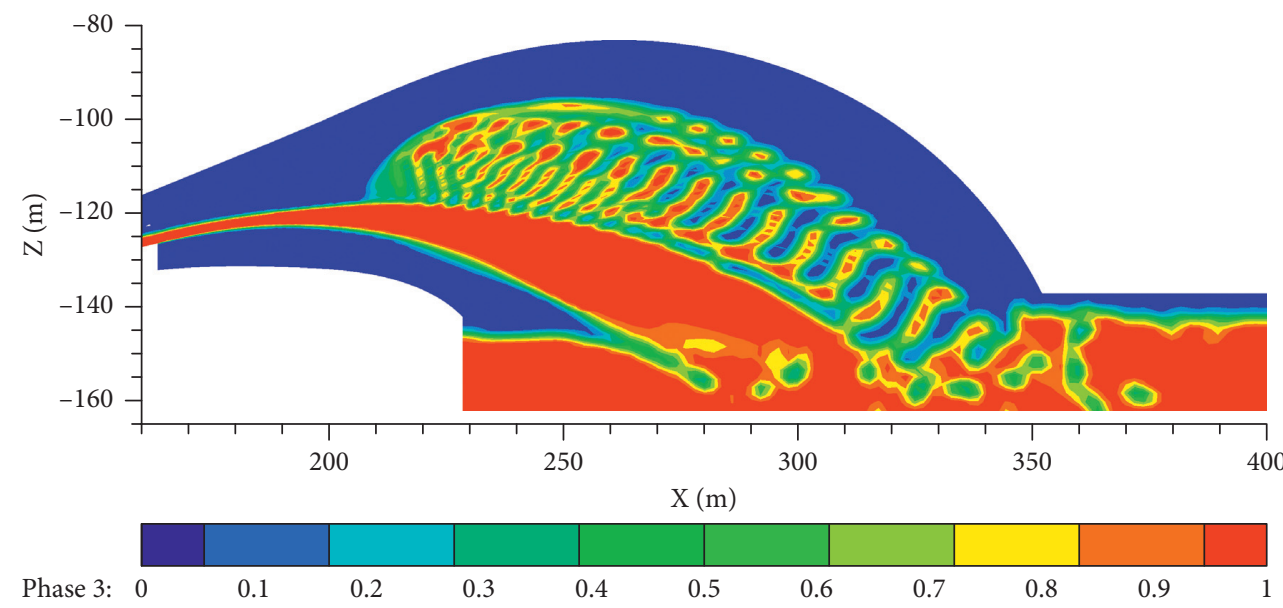

(a)

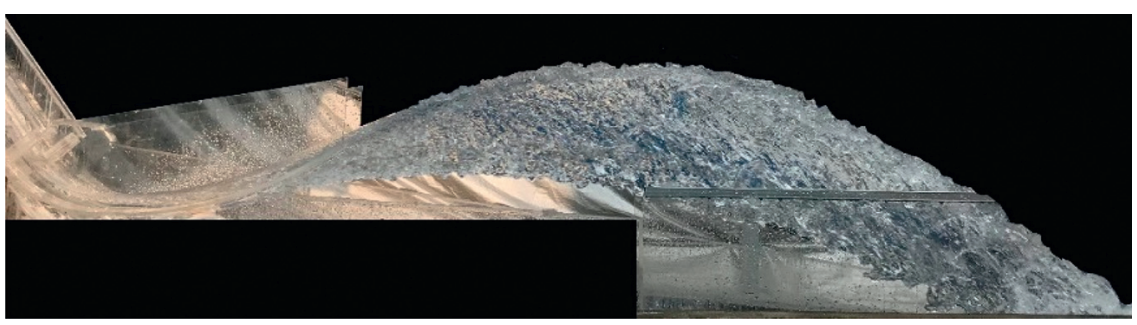

(b)

Figure 5: Continued. 


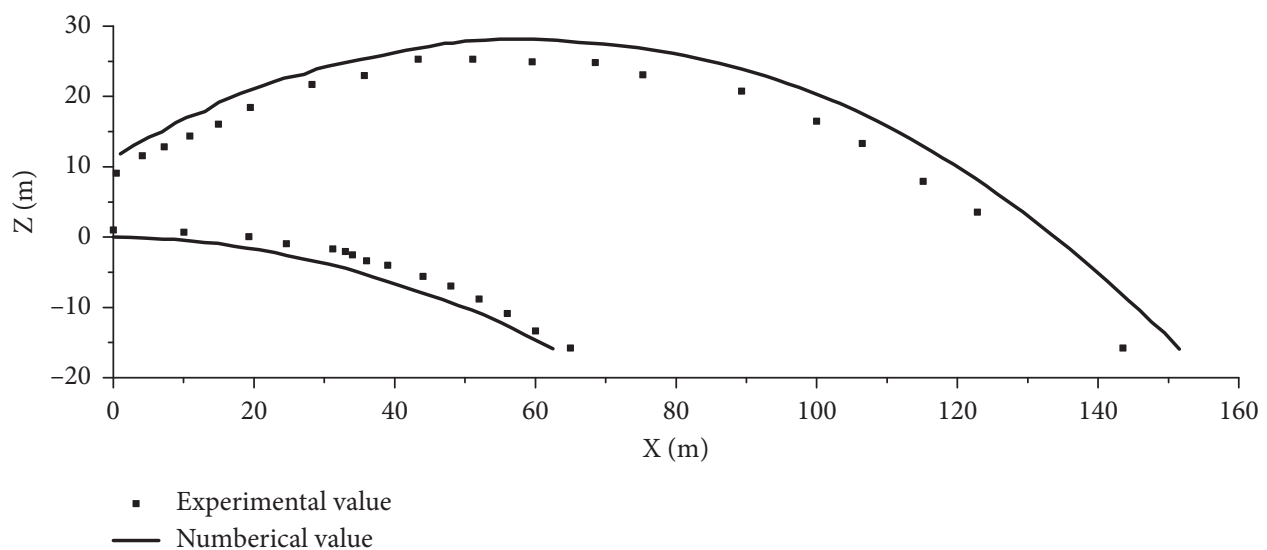

(c)

FIGURE 5: Water nappe flow patterns: (a) numerical simulation; (b) experiment; (c) comparison.

TABLE 4: Comparison of inner and outer trajectory distances.

\begin{tabular}{lccc}
\hline Characteristic parameter & Experimental value & Numerical value & Relative error (\%) \\
\hline Inner trajectory distance $L_{1}(\mathrm{~m})$ & 65 & 62.5 & -3.85 \\
Outer trajectory distance $L_{2}(\mathrm{~m})$ & 143.5 & 151.56 & 5.62 \\
\hline
\end{tabular}

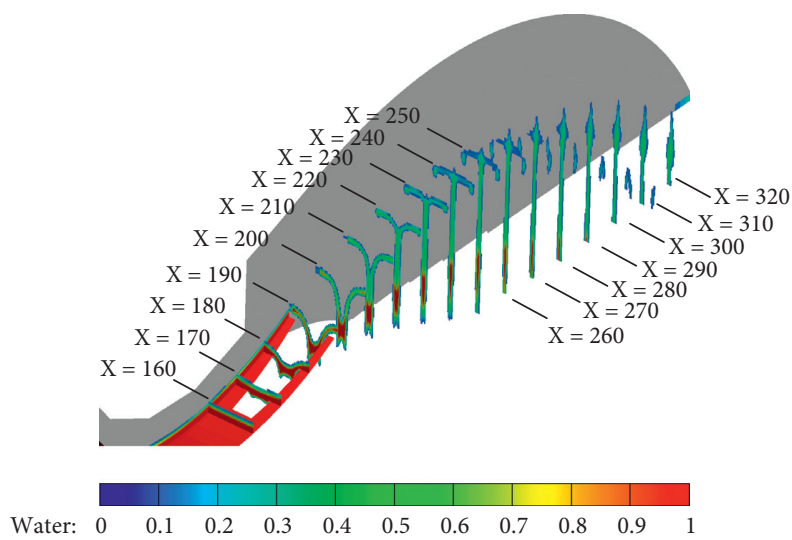

(a)

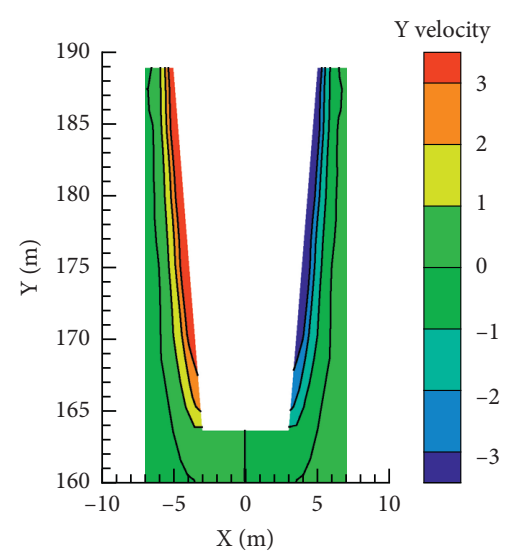

(b)

FIGURE 6: Transversely moving water nappe: (a) aerial flow pattern of water nappe (unit: m); (b) Y velocity contour of flow near the bottom plate.

3.1. Bucket Water Depth. Figure 7 shows the water depth at the $Y=6 \mathrm{~m}$ section with different upstream opening widths. It can be seen that the water depth decreases with the increase of the upstream opening width $\left(B_{1}\right)$ as more water flows out of the gap in the middle and less water flows along each side of the flip bucket. Due to the widening of the gap along the flow direction, the descending rate of water depth accelerates with the increase of upstream opening width $\left(B_{1}\right)$.

3.2. Inner and Outer Trajectories of Water Nappe. Figure 8 shows the inner and outer trajectories with different upstream opening widths of the gap. There is little difference in the outer trajectory of water nappe. The outer trajectory distance decreases with the increase of the opening width. However, the inner trajectory distance increases as the opening width increases. The reason is that the smaller the opening width is, the less water flows out of the middle gap and the larger the squeezing force of the water flows on both sides is, which causes the water to move transversely. Therefore, the envelope of the water trajectory downstream for $B_{1}=4 \mathrm{~m}$ is the greatest among the three cases.

Figure 9(a) shows the trajectories of water nappe with different downstream bucket angles of the gap. First of all, the trajectories of the four cases are plotted in the same coordinate system, ignoring the factor that the length of the bucket varies due to different bucket angles. It can be seen that the downstream bucket angle has little effect on the inner trajectory but has a great impact on the outer 


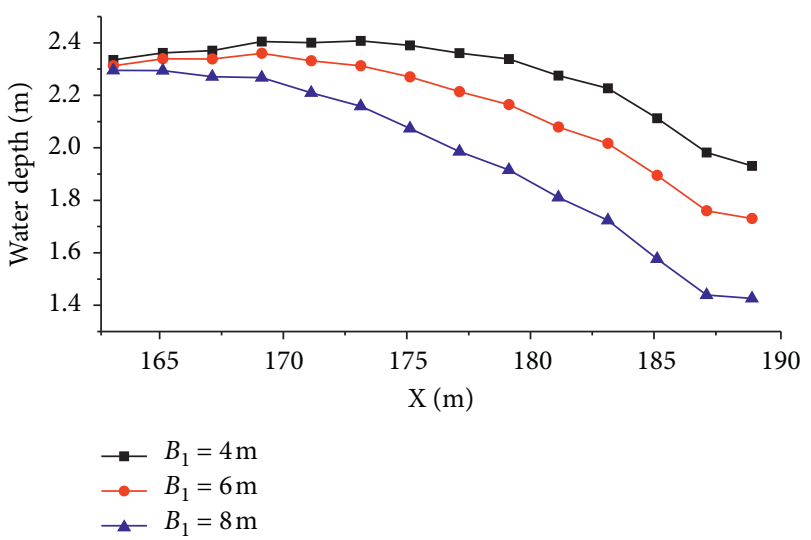

Figure 7: Comparison of water depth in the bucket section for different opening widths of the gap.

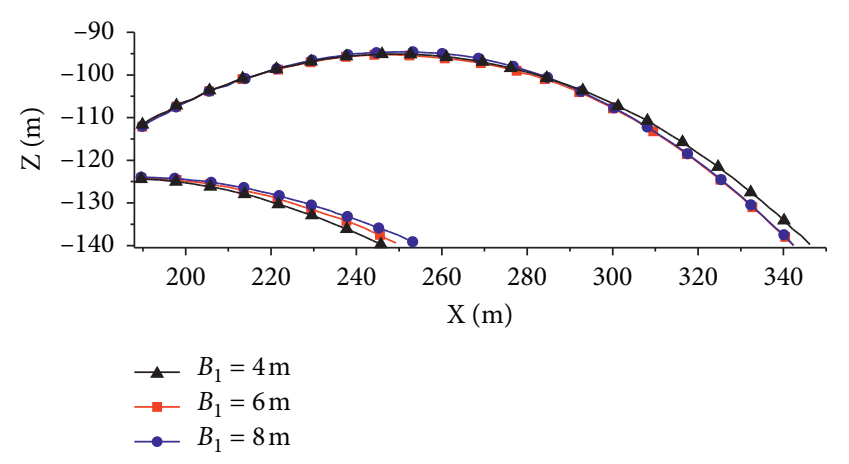

FIGURE 8: Trajectories of water nappe with different upstream opening widths of the gap.

trajectory. The outer trajectory distance increases with the increase of the downstream bucket angle. The larger the downstream bucket angle is, the longer the length of flip bucket will be. After water jet stretches sufficiently longitudinally of the swallow-tailed flip bucket, more water in the upper portion can be ejected from the end of the bucket. This makes the outer trajectory to rise. The outer trajectory falling point overlaps each other when the bucket angle equals to $35^{\circ}$ and $40^{\circ}$, indicating that the outer trajectory distance decreases when the downstream bucket angle exceeds $35^{\circ}$. Secondly, in order to take into account the variation of the bucket length, the origins of each trajectory are set at the outlet of each flip bucket (Figure 9(b)), showing the computed jet trajectory distance and stretching length $\left(L_{\mathrm{S}}\right)$ of the four cases. Stretching length $\left(L_{S}\right)$ is defined as the outer trajectory distance $\left(L_{2}\right)$ minus the inner trajectory distance $\left(L_{1}\right)$. It can be concluded that the inner trajectory distance $\left(L_{1}\right)$ decreases slightly with the increase of the downstream bucket angle. The outer trajectory distance $\left(L_{2}\right)$ increases firstly and then decreases. The stretching length increases gradually.

Dimensional analysis is conducted to derive the trajectory of water particle in the air. In the present study, the jet trajectory could be expressed in terms of the variables in the following function:

$$
y=f\left(x, \theta, g, v, \frac{B_{1}}{B}\right)
$$

where $y(\mathrm{~m})$ is the vertical distance from the water particle to the exit point; $x(\mathrm{~m})$ is the horizontal distance from the water particle to the exit point; $\theta\left(^{\circ}\right)$ is the bucket angle; $g\left(\mathrm{~m} / \mathrm{s}^{2}\right)$ is the gravity acceleration; $v(\mathrm{~m} / \mathrm{s})$ is the average velocity at the exit cross-section; $B_{1} / B$ is the ratio of the upstream opening width over the gap. Applying the Buckingham $\pi$-theorem to equation (10):

$$
\frac{y}{x}=f\left(\frac{v^{2}}{g x}, \theta, \frac{B_{1}}{B}\right)
$$

According to the particle projectile theory [19], the abovementioned equation can be simplified as the following equation:

$$
\frac{y}{x}=a\left(\frac{B_{1}}{B}\right)^{b} \tan ^{c} \theta-d \frac{g x}{2 v^{2} \cos ^{e} \theta}\left(\frac{B_{1}}{B}\right)^{f},
$$

where $a, b, c, d, e$, and $f$ are dimensionless coefficients. When calculating the outer trajectory, the bucket angle $(\theta)$ is replaced by the downstream bucket angle of the gap $\left(\theta_{2}\right)$. Five dimensionless coefficients are obtained by fitting the data of the abovementioned six cases. The outer trajectory equation is shown below:

$$
\frac{y}{x}=\left(\frac{B_{1}}{B}\right)^{0.05} \tan ^{1.36} \theta_{2}-0.73 \frac{g x}{2 v^{2} \cos ^{3.9} \theta_{2}}\left(\frac{B_{1}}{B}\right)^{0.073},
$$

where $\theta_{2}\left({ }^{\circ}\right)$ is the downstream bucket angle of the gap. The range of the abovementioned equation is $2 / 7 \leq B_{1} / B \leq 4 / 7$, $25^{\circ} \leq \theta_{2} \leq 40^{\circ}$.

When calculating the inner edge trajectory, the bucket angle $(\theta)$ is replaced by the upstream bucket angle of the gap $\left(\theta_{1}\right)$. As the variation of the upstream bucket angle of the gap is not investigated in this paper, the value of the coefficient $c$ is taken as 1 and the value of the coefficient $b$ is taken as 2 based on the particle projectile theory. The inner trajectory equation is obtained by fitting the data of Case 1 , Case 2 , and Case 3. Range of equations is $2 / 7 \leq B_{1} / B \leq 4 / 7$. The curve fitting of inner and outer trajectories is shown in Figure 10.

$$
\frac{y}{x}=0.67\left(\frac{B_{1}}{B}\right)^{0.01} \tan \theta_{1}-0.9 \frac{g x}{2 v^{2} \cos ^{2} \theta_{1}}\left(\frac{B_{1}}{B}\right)^{-0.2} \text {. }
$$

3.3. Unit Discharge Distribution. Figure 11 shows the patterns of the water nappe entry at plane $Z=-140 \mathrm{~m}$ with different upstream opening widths of the gap. The volume fraction of the water contour line is 0.1 . It is obvious that the water nappe is long strip shaped, which is consistent with the conclusion that the water nappe is "I-type" in the air. If the water nappe is always "Y-type" in the air, the upper portion of the water jet will fall into the plunge pool separately, resulting in the pattern being not long strip shaped. At the end of the water nappe entry, it is a little wider than the other parts, caused by the two water jets ejecting from the outlet of 


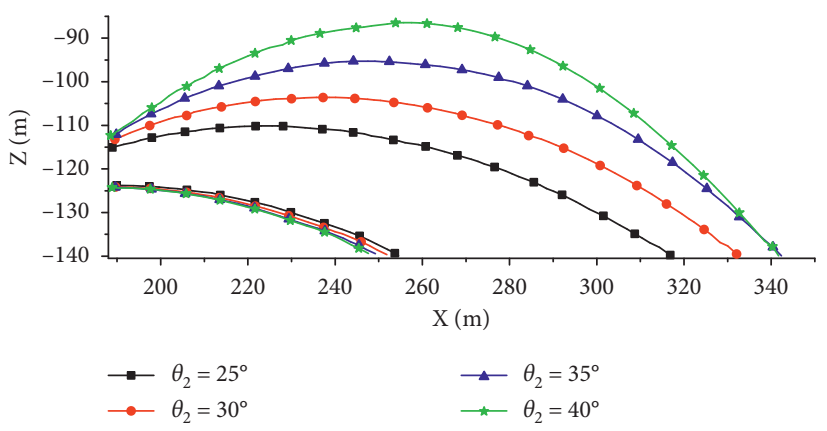

(a)

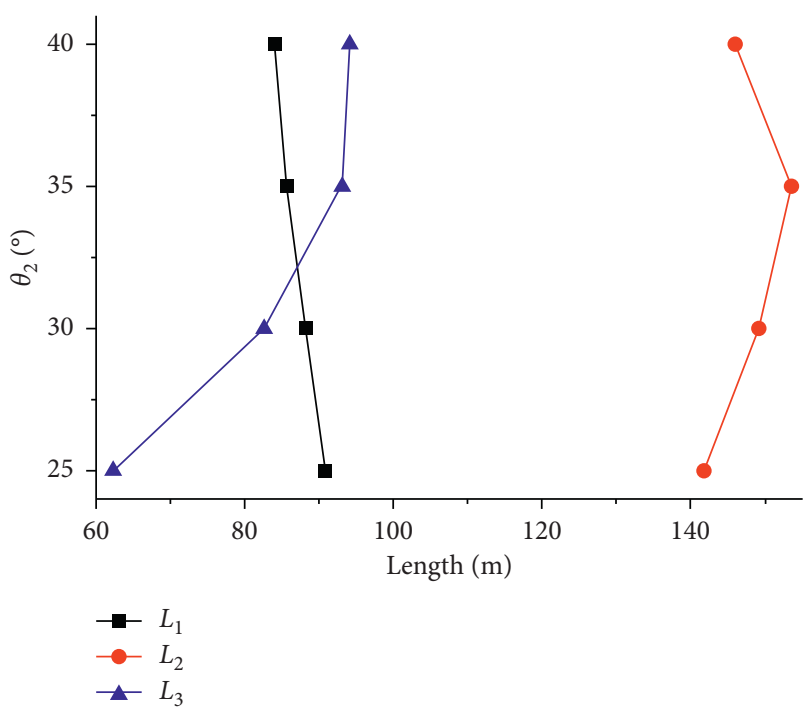

(b)

FIGURE 9: Jet trajectory distance and longitudinal stretching length, (a) ignoring the variation of the bucket length in the same coordinate and (b) taking into account the variation of the bucket length in different coordinates.

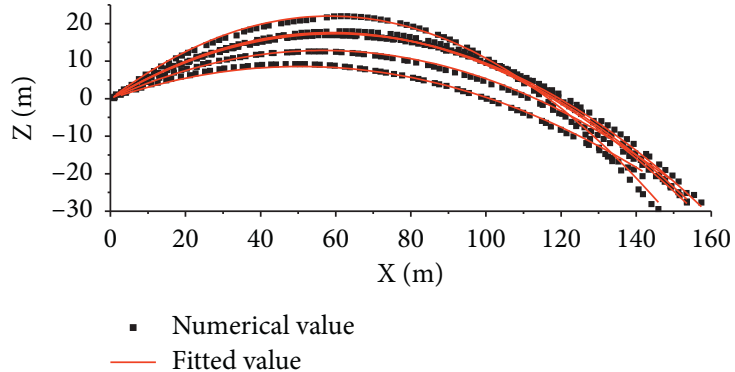

(a)

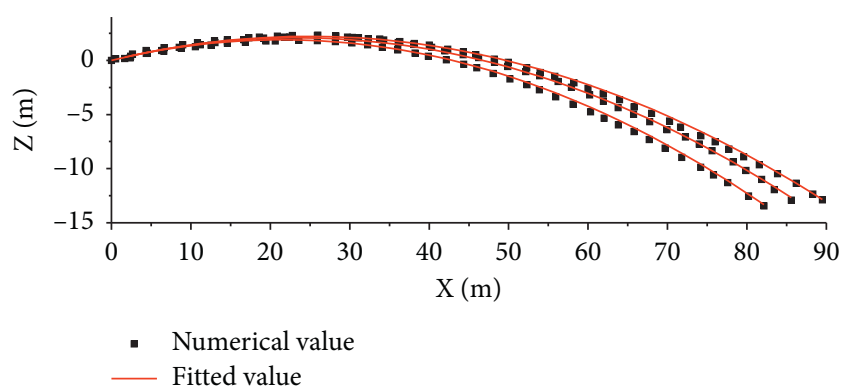

(b)

FIgURE 10: Curve fitting: (a) the outer trajectory; (b) the inner trajectory.

the flip bucket on each side. It can be seen from Figure 11 that the length of water nappe entry reaches the largest when $B_{1}=4 \mathrm{~m}$. With the decrease of $B_{1}$, the water jet is stretched more fully in the longitudinal direction. The length of the water nappe entry increases, while the width decreases, indicating that the water nappe is more dispersed. With the increase of the upstream opening width ratio of $B_{1} / B$, the longitudinal stretching length of water nappe entry decreases.

Figure 12 shows the patterns of the water nappe entry at plane $Z=-140 \mathrm{~m}$ with different downstream bucket angles of the gap, which are long strip shaped. The distribution range is consistent with the aforementioned about the falling point of the inner and outer water nappe edges. With the increase of the downstream bucket angle, the length of the water nappe entry pattern increases while the width decreases, indicating that the water flow is more dispersive.

For the pattern of the water nappe entry is long strip shaped, the unit discharge is used to represent the longitudinal discharge distribution. The water nappe entry is divided into several areas with a certain length interval along the flow direction. The unit discharge is defined as the total discharge divided by each area by the length interval, as shown in Figure 13. According to Figure 13(a), although the stretching length is long, the discharge mainly concentrates in the tail when $B_{1}=4 \mathrm{~m}$. Moreover, the maximum unit discharge is the largest in the three working conditions, and the discharge is lower than the others in the front middle area. Such uneven discharge distribution leads to large impact pressure on the bottom plate of the plunge pool, which is not conducive to practical projects. When $B_{1}=8 \mathrm{~m}$, the discharge is evenly distributed, but the distribution range is the smallest among the three operating conditions. The working condition of $B_{1}=6 \mathrm{~m}$ has an ideal unit discharge distribution of water nappe entry.

Figure 13(b) shows the unit discharge distribution of water nappe entry with different downstream bucket angles of the gap. It can be found that in the front middle part of the water nappe, the discharge of the four angles is almost uniformly distributed. In the tail, when $\theta_{2}=30^{\circ}$, the discharge is roughly equal to that of the front middle area. 


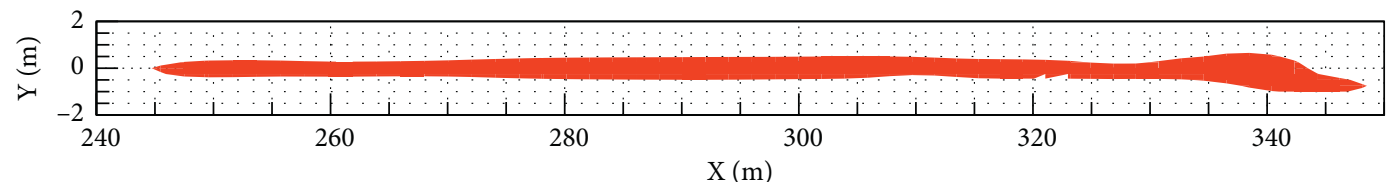

(a)

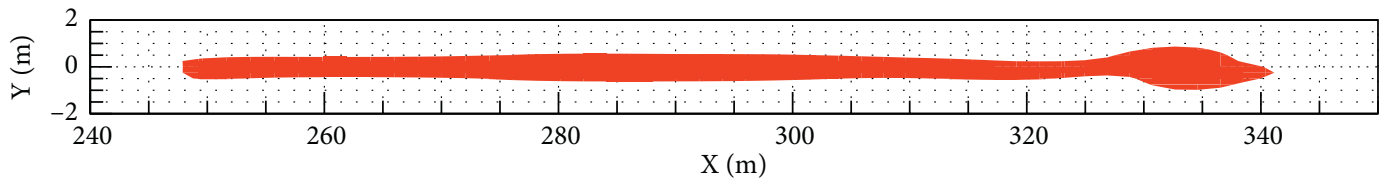

(b)

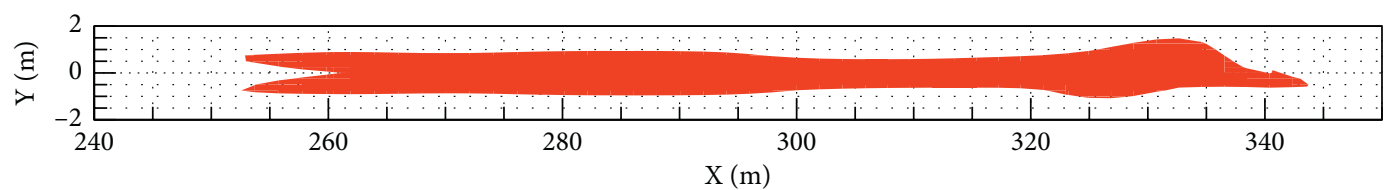

(c)

FIGURE 11: The patterns of the water nappe entry with different upstream opening widths: (a) $B_{1}=4 \mathrm{~m}$; (b) $B_{1}=6 \mathrm{~m}$; (c) $B_{1}=8 \mathrm{~m}$.

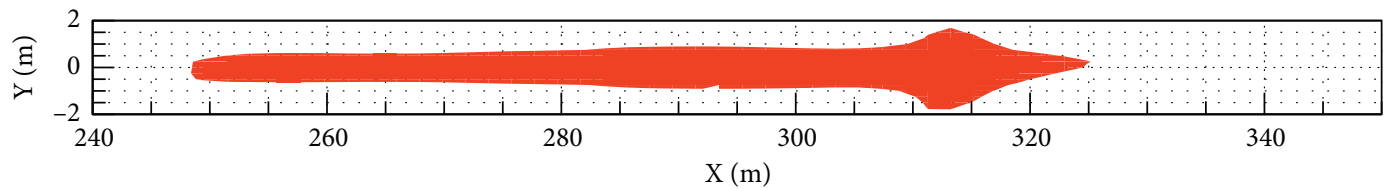

(a)

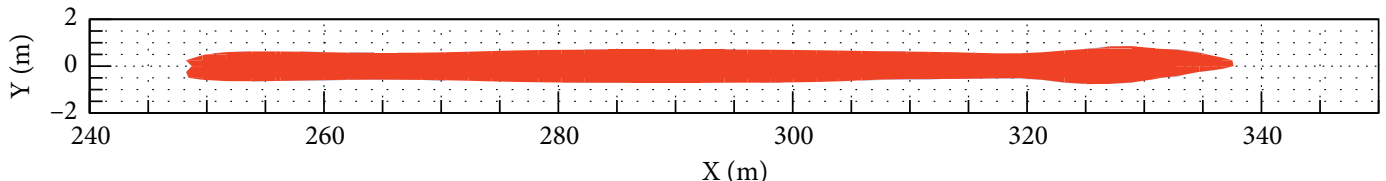

(b)

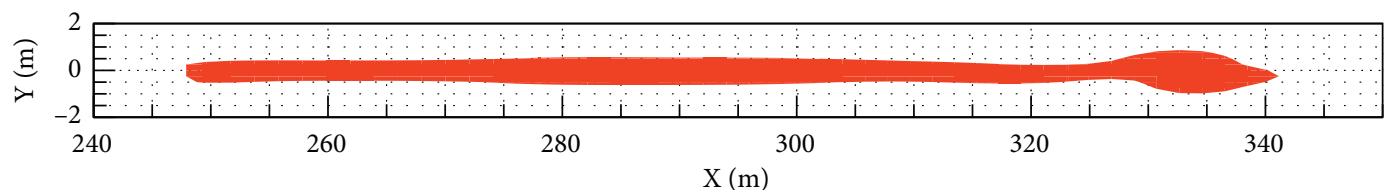

(c)

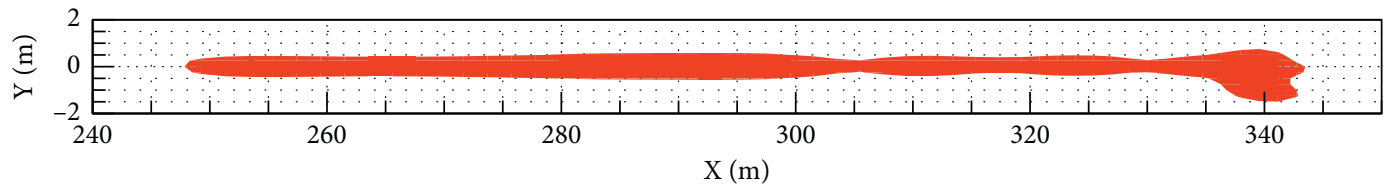

(d)

FiguRE 12: The patterns of the water nappe entry with different downstream bucket angles: (a) $\theta_{2}=25^{\circ}$; (b) $\theta_{2}=30^{\circ}$; (c) $\theta_{2}=35^{\circ}$; (d) $\theta_{2}=40^{\circ}$.

There are obvious peaks in the other three working conditions, about twice as much as that of the front middle area. Above all, the working condition of $\theta_{2}=30^{\circ}$ has an ideal unit discharge distribution of water nappe entry.

3.4. Flow Field Distribution. In this section, Case 1 is taken as a typical working condition. After the trajectory motion through air, the water jet enters into the downstream plunge pool as a submerged jet. The plunge of jet generates strong turbulence in the plunge pool with partial backflow and whirlpool. Part of the kinetic energy of the water jet is converted into pressure energy, which extends to the bottom of the pool and generates great pressure there, as shown in Figure 14(a). Figure 14(b) shows the flow field on the $Z=-150 \mathrm{~m}$ cross-section, which is located at the half of the total water depth in the plunge pool. At this time, the jet starts to collide with the downstream water. As can be seen 


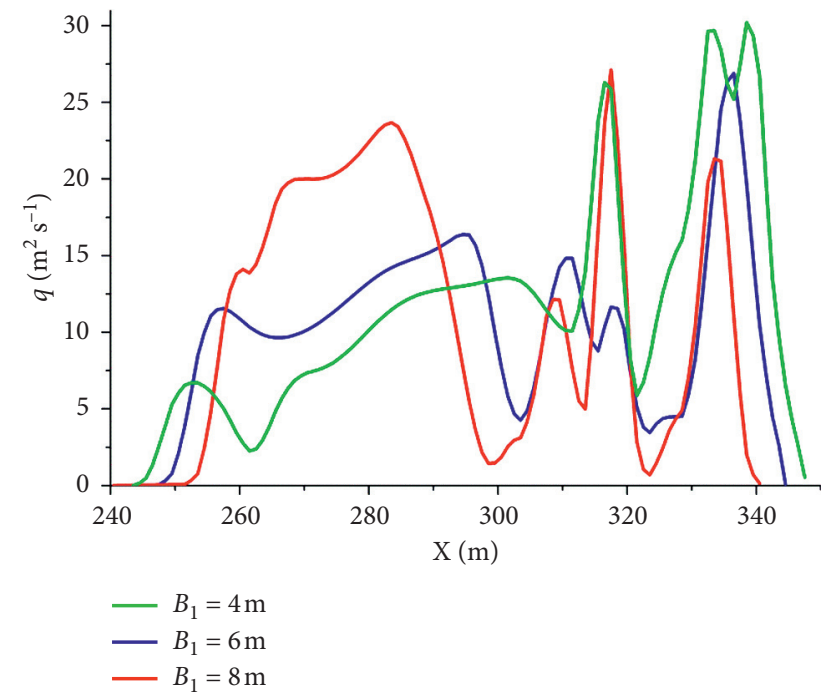

(a)
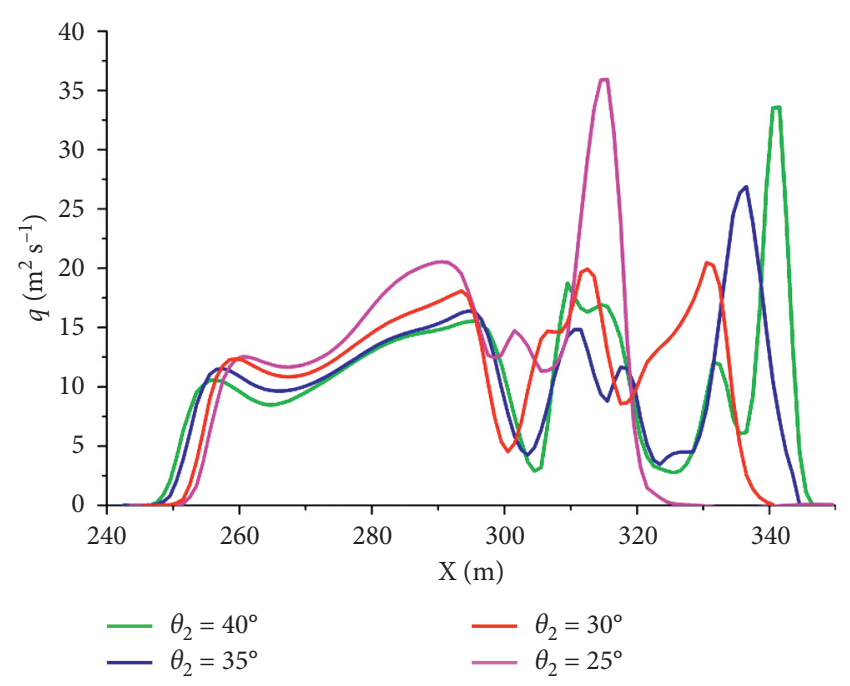

(b)

FIGURE 13: Unit discharge distribution of water nappe entry with different shape parameters: (a) variation of upstream opening width; (b) variation of downstream bucket angle.
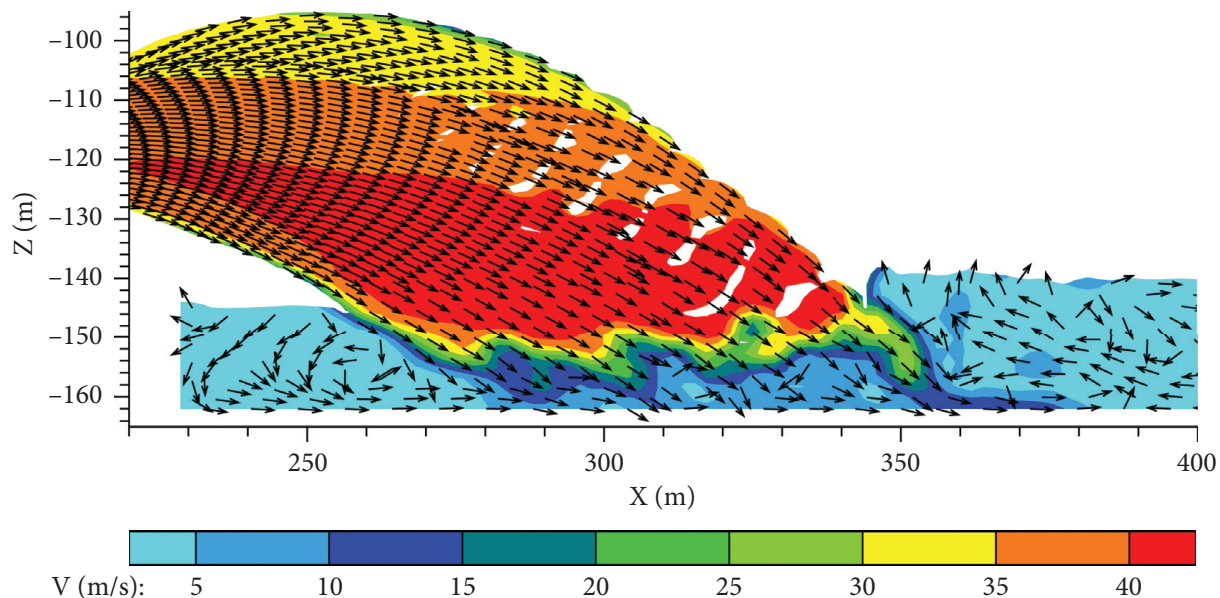

(a)
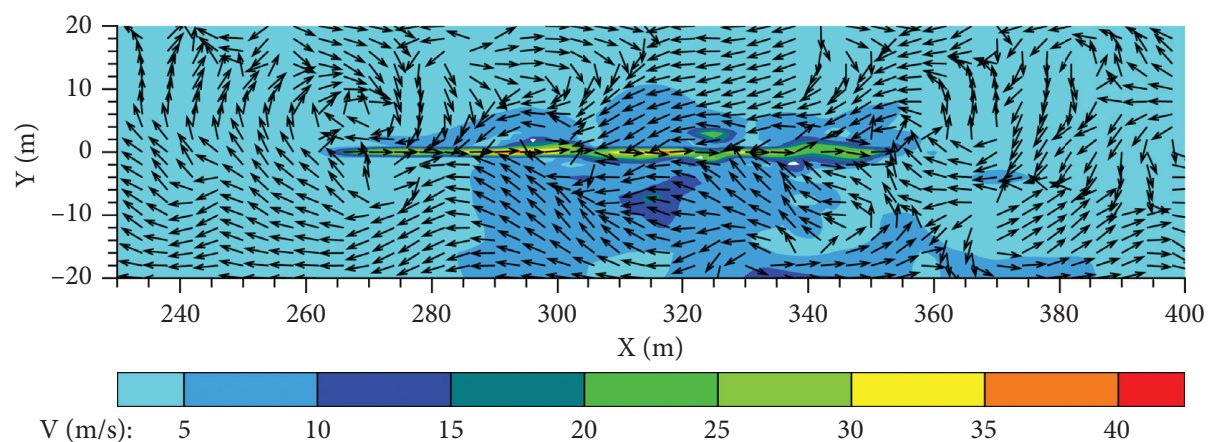

(b)

Figure 14: Continued. 

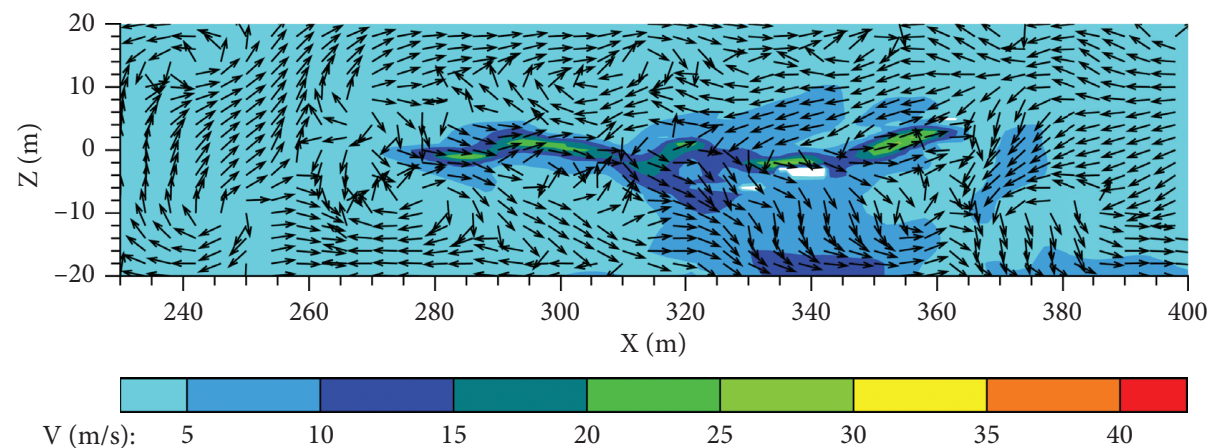

(c)

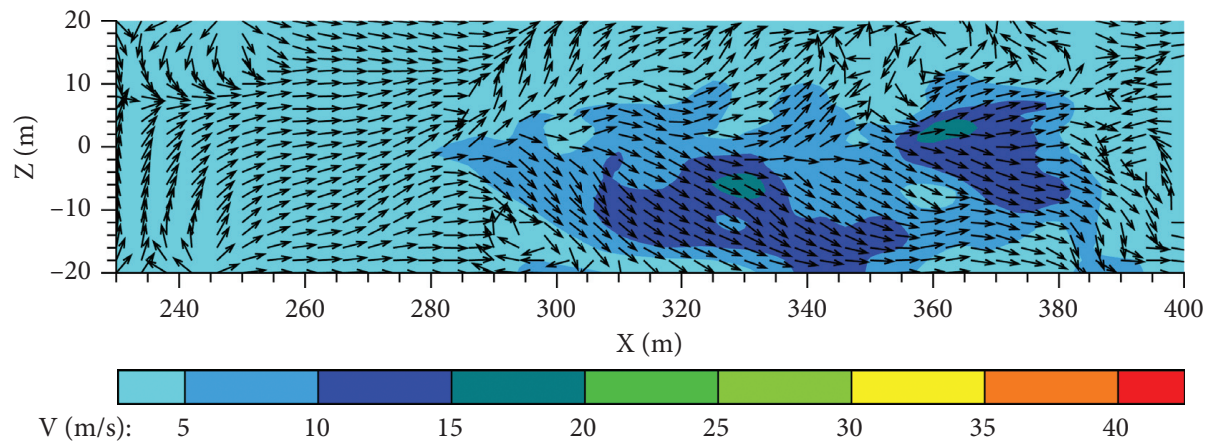

(d)

Figure 14: Velocity vectors in typical profiles: (a) $Y=0 \mathrm{~m}$ cross-section; (b) $Z=-150 \mathrm{~m}$ cross-section; (c) $Z=-156 \mathrm{~m}$ cross-section; (d) $Z=-162 \mathrm{~m}$ cross-section.

from the velocity contour, the velocity core area has a long strip shape with velocity being over $40 \mathrm{~m} / \mathrm{s}$. Figure 14 (c) shows the flow field at $6 \mathrm{~m}$ above the bottom plate. It can be seen that the velocity core area is distorted, and the velocity has been greatly reduced after colliding with water cushion. Figure 14(d) shows the flow field near the bottom plate, indicating that there is no obvious velocity core area at the bottom of the pool. This means that almost all the kinetic energy of the jet flow has been basically transferred through impact and collision as well as vortex generation. The overall water flows downstream.

3.5. Impact Pressure Distribution. The maximum pressure coefficient is introduced to evaluate the energy dissipation at the plunge pool. The maximum pressure coefficient is defined as

$$
C_{p}=\frac{H_{m}}{U_{j}^{2} /(2 g)}
$$

where $C_{p}$ is the maximum pressure coefficient; $H_{m}$ is the maximum impact pressure head in the plunge pool; $U_{J}$ is the jet entry velocity.

As shown in Figure 15, the coefficient $C_{p}$ of Case 5 $\left(B_{1}=6 \mathrm{~m}, \theta_{2}=30^{\circ}\right)$ is the smallest, indicating that both of the shape parameters should be chosen as their intermediate values.

Figure 16 shows the pressure distribution of the continuous bucket and swallow-tailed flip bucket in the plunge

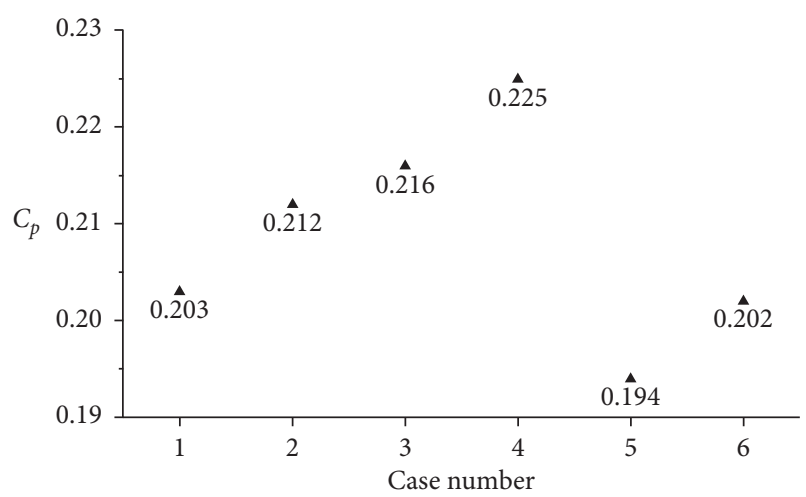

FIGURE 15: The maximum pressure coefficients for different cases.

pool. It can be seen that the traditional continuous bucket cannot fully diffuse the water nappe, which enters into the plunge pool with relatively concentrated profile, causing the pressure gradient in the small impact area increase sharply, and the pressure distribution is in the shape of "inverted V," as shown in Figures 15(a) and 15(b). As a result, the relatively concentrated submerged jet will cause potential scour in the plunge pool. It is also seen that the pressure distribution is similar to the discharge distribution. Under the four working conditions, the working condition with the lowest peak pressure is $B_{1}=6 \mathrm{~m}$, and the pressure head is $25.47 \mathrm{~m}$, which is about $20.3 \%$ of the inlet total head $(125.28 \mathrm{~m})$. Results show that if the opening width ratio is 


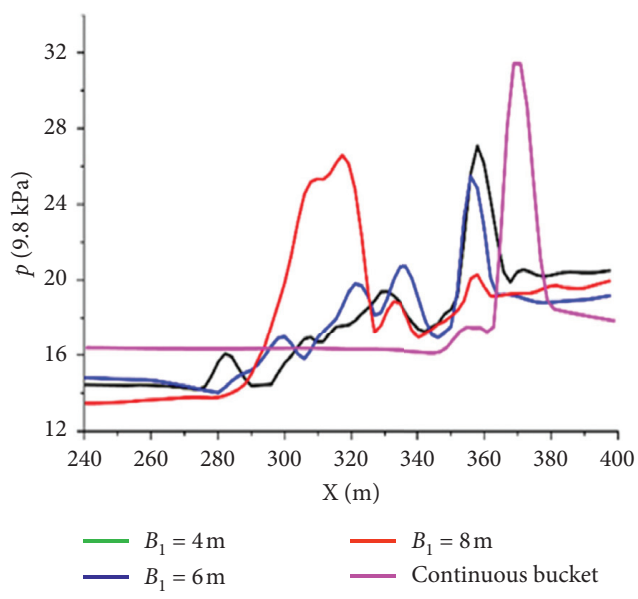

(a)

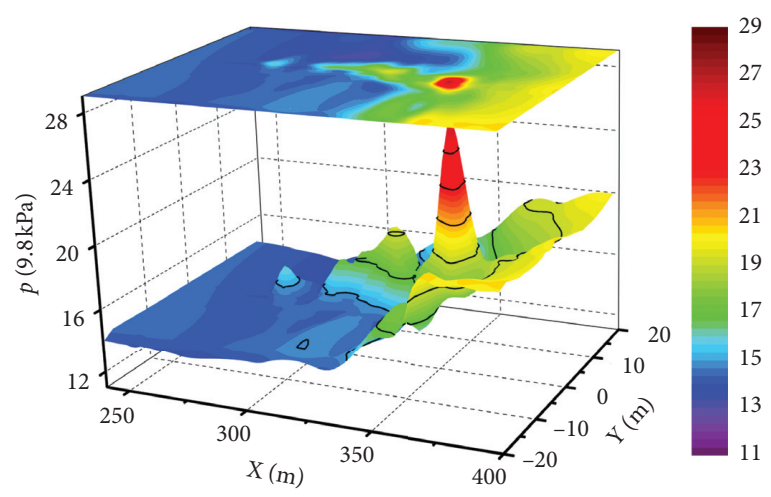

(c)

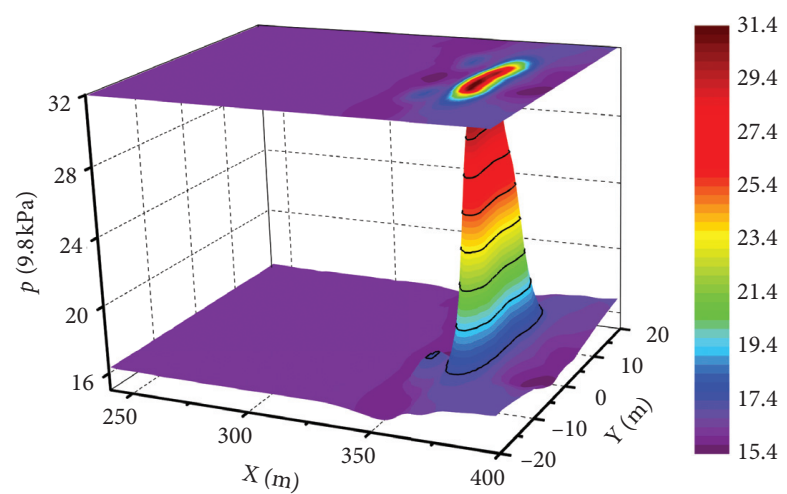

(b)

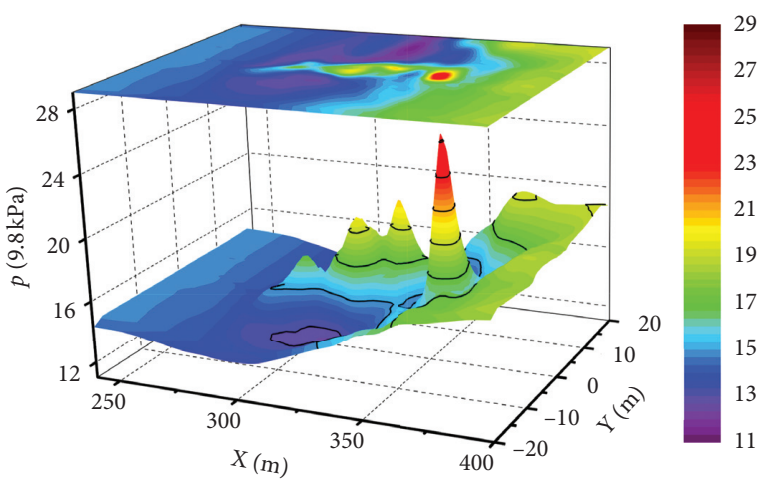

(d)

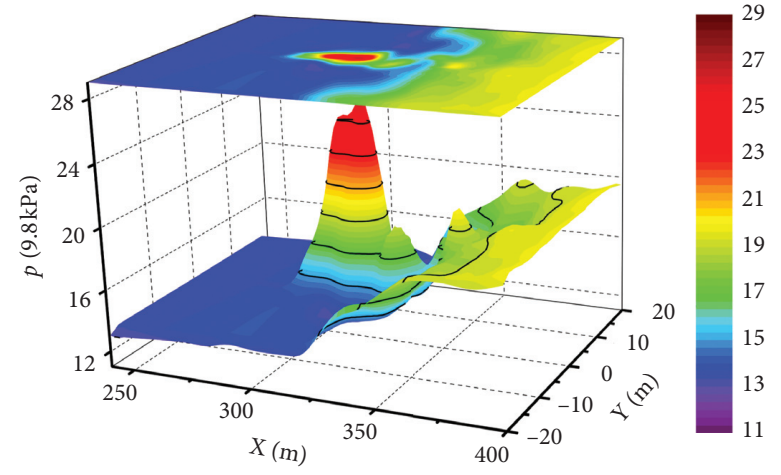

(e)

Figure 16: Pressure distribution of the continuous bucket and swallow-tailed flip bucket with different opening widths in the plunge pool: (a) pressure distribution along the central axis; (b) continuous bucket; (c) $B_{1}=4 \mathrm{~m}$; (d) $B_{1}=6 \mathrm{~m}$; (e) $B_{1}=8 \mathrm{~m}$.

too large, more water will eject from the front gap of the bucket, resulting in more water distribution in the front area. If the opening width ratio is too small, more water will eject at a larger angle and drop at the further area, resulting in more water distribution in the tail area. Such uneven stretching of the water nappe will lead to a larger peak pressure.

Figure 17 shows the pressure distribution with different downstream bucket angles of the gap. It is seen that the lowest peak pressure takes place for $\theta_{2}=30^{\circ}$ with the pressure water head being $24.35 \mathrm{~m}(19.4 \%$ of the inlet total head). In the other three working conditions, if the downstream bucket angle is smaller than $30^{\circ}$, the pressure distribution range gets smaller, so the pressure distribution is more concentrated. If the downstream bucket angle is larger than $30^{\circ}$, unit discharge gets larger in the tail area, resulting in a bigger peak pressure in the tail area. It can be concluded that uneven discharge distribution will cause 


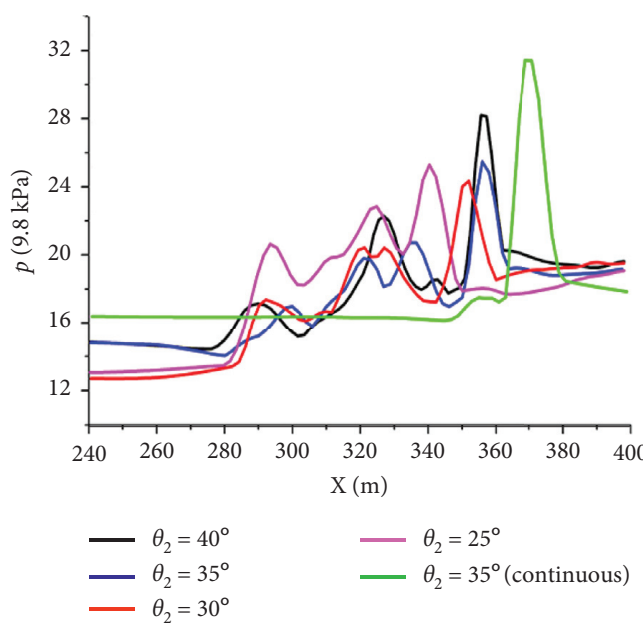

(a)

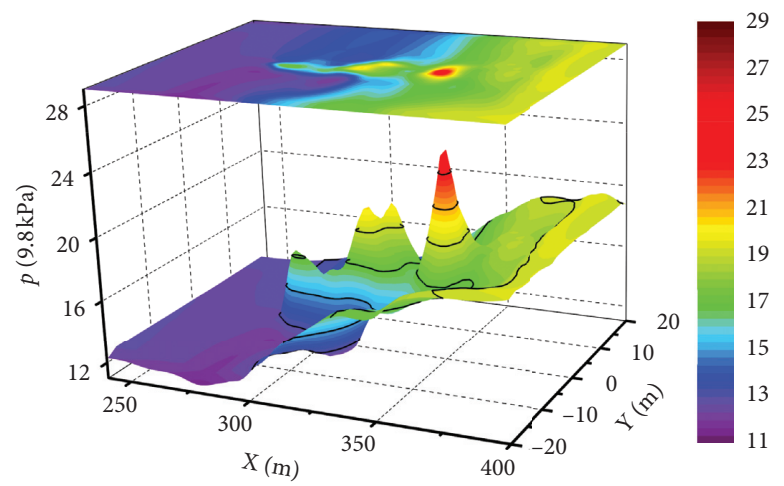

(c)

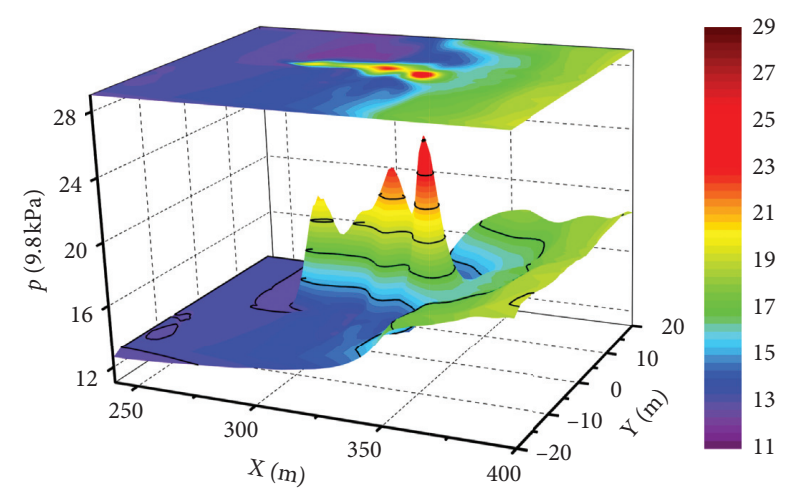

(b)

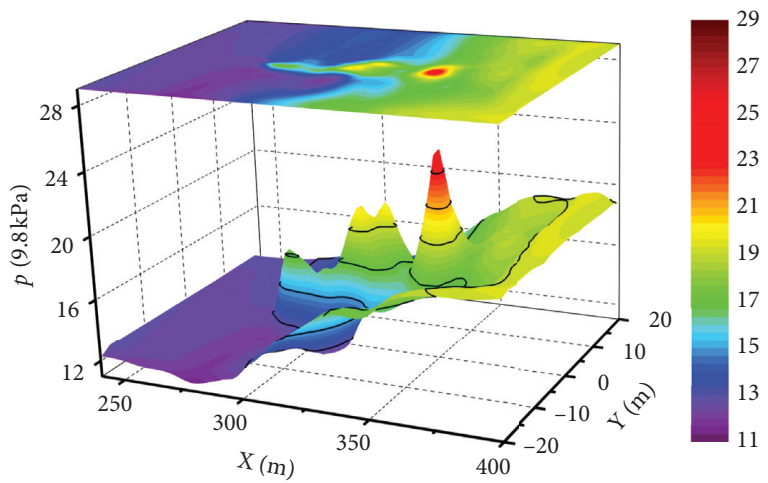

(d)

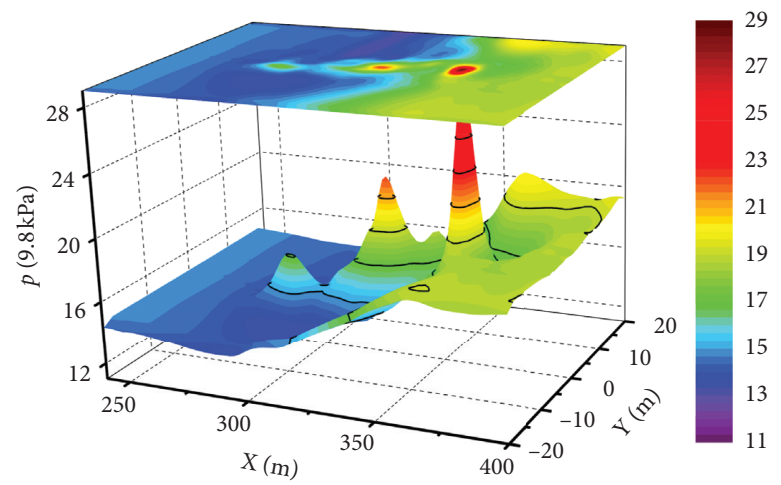

(e)

Figure 17: Pressure distribution in the plunge pool with different downstream bucket angles: (a) pressure distribution along the central axis; (b) $\theta_{2}=25^{\circ}$; (c) $\theta_{2}=30^{\circ}$; (d) $\theta_{2}=35^{\circ}$; (e) $\theta_{2}=40^{\circ}$.

uneven pressure distribution. Therefore, it is of great signification to adjust the shape parameters of the swallowtailed flip bucket to obtain even discharge distribution to avoid destruction of the plunge pool floor.

\section{Conclusions}

Compared with the previous studies, this paper innovatively proposes the inner and outer trajectories and investigates the unit discharge distribution and impact pressure distribution. The hydraulic characteristics and impact characteristics of the swallow-tailed flip bucket with different upstream opening widths and downstream bucket angles of the gap are investigated by using the standard $k-\varepsilon$ turbulence model and laboratory experiments. The main conclusions from this study can be drawn as follows:

(1) According to the simulation results, considering the influence of the opening width ratio and downstream 
bucket angle of the gap on the trajectories, a modified formula is established to calculate the trajectories, which can be used to predict the water jet trajectory with good accuracy.

(2) The takeoff characteristics of water nappe: the inner trajectory distance increases with the increase of the opening width ratio of the gap and decreases with the increase of the downstream bucket angle of the gap. The outer trajectory distance increases with the decrease of the opening width ratio of the gap and increases first and then decreases with the increase of the downstream bucket angle of the gap.

(3) The impact characteristics of the swallow-tailed flip bucket: due to the long strip shape of the water entry pattern, the unit discharge distribution is consistent with the pressure distribution on the plunge pool bottom plate. The opening width ratio and downstream bucket angle should not be too large or too small. Therefore, in practical application, the shape parameters need to be adjusted according to different incoming flow conditions and engineering layout. In this paper, the ideal cases are $B_{1} / B=0.429$ and $\theta_{2}=30^{\circ}$.

4.1. Limitations and Practical Application. The accuracy of the inner and outer trajectories may be affected by the volume fraction of water and numerical scheme adopted. Due to the data collection, the proposed formula will be required to be further applied to other practical engineering projects to verify its applicability. The swallow-tailed flip bucket has been applied to the Jinping Hydropower Station and the Huangdeng Hydropower Station, which has achieved good effect of water nappe stretching and energy dissipation.

\section{Data Availability}

Some or all data, models, or codes generated or used during the study are available from the first author upon request (Lifang Zhang: 2017223060052@stu.scu.edu.cn).

\section{Conflicts of Interest}

The authors declare that they have no conflicts of interest.

\section{Acknowledgments}

This work was supported by the National Science Fund for Distinguished Young Scholars (no. 51625901) and National Nature Science Foundation of China (no: 51579165).

\section{References}

[1] V. Heller, W. H. Hager, and H.-E. Minor, "Ski jump hydraulics," Journal of Hydraulic Engineering, vol. 131, no. 5, pp. 347-355, 2005.

[2] W. Xu, H. Liao, Y. Yang, and C. Wu, "Turbulent flow and energy dissipation in plunge pool of high arch dam," Journal of Hydraulic Research, vol. 40, no. 4, pp. 471-476, 2002.
[3] L. Schmocker, M. Pfister, W. H. Hager, and H.-E. Minor, "Aeration characteristics of ski jump jets," Journal of $\mathrm{Hy}$ draulic Engineering, vol. 134, no. 1, pp. 90-97, 2008.

[4] J. Puertas and J. Dolz, "Plunge pool pressures due to a falling rectangular jet," Journal of Hydraulic Engineering, vol. 131, no. 5, pp. 404-407, 2005.

[5] J.-h. Wu, F. Ma, and L. Yao, "Hydraulic characteristics of slittype energy dissipaters," Journal of Hydrodynamics, vol. 24, no. 6, pp. 883-887, 2012.

[6] N. A. Alias, T. A. Mohamed, A. H. Ghazali, and M. J. M. M. Noor, "Impact of takeoff angle of bucket type energy dissipater on scour hole," American Journal of Applied Sciences, vol. 5, no. 2, pp. 117-212, 2008.

[7] J. Deng, Z. Yang, Z. Tian et al., "A new type of leak-floor flip bucket," Science China Technological Sciences, vol. 59, no. 4, pp. 565-572, 2015.

[8] X. Qian, Research on Characteristics of Swallow-Tail Bucket. Master Degree, Sichuan University, Chengdu, China, 2012, in Chinese.

[9] D. Mao, F. Zhang, X. Zhong, and M. Lv, “Application test of swallow-tailed flip bucket ski-jump energy dissipation for Huangdeng hydropower station," Water Resources Power, vol. 34, no. 3, pp. 104-107, 2016, in Chinese.

[10] J. Wang, J. Deng, L. Lv, and Z. Yang, "Hydraulic characteristics of swallow-tailed array flip buckets," Journal of Hydraulic Engineering, vol. 36, pp. 31-37, 2017, in Chinese.

[11] G. Li, X. Li, J. Ning, and Y. Deng, "Numerical simulation and engineering application of a dovetail-shaped bucket," Water, vol. 11, no. 2, p. 242, 2019.

[12] M. Karami Moghadam, A. Amini, M. A. Malek, T. Mohammad, and H. Hoseini, "Physical modeling of skijump spillway to evaluate dynamic pressure," Water, vol. 11, no. 8, p. 1687, 2019.

[13] P. Xia, "3-D numerical simulation on the spillway tunnel with Dovetail-shaped flip bucket," China Rural Water Hydropower, vol. 2015, pp. 124-128, 2015, in Chinese.

[14] P. Liu and W. Xu, "Study on non-impact energy dissipation of ski-drop flow in plunge pool of high arch dam," Journal of Hydraulic Engineering, vol. 41, pp. 841-848, 2010, in Chinese.

[15] J. Deng, W. Wei, Z. Tian, and F. Zhang, "Design of A Streamwise-Lateral ski-jump flow discharge spillway," Water, vol. 10, no. 11, p. 1585, 2018.

[16] B. Launder and B. Spalding, Lectures in Mathematical Model of Turbulence, Academic Press, London, UK, 1972.

[17] C. W. Hirt and B. D. Nichols, "Volume of fluid (VOF) method for the dynamics of free boundaries," Journal of Computational Physics, vol. 39, no. 1, pp. 201-225, 1981.

[18] I. Celik, U. Ghia, P. J. Roache, C. Freitas, H. Coloman, and P. Raad, "Procedure for estimation and reporting of uncertainty due to discretization in CFD applications," Journal of Fluids Engineering, vol. 130, Article ID 078001, 2008.

[19] R. Juon and W. H. Hager, "Flip bucket without and with deflectors," Journal of Hydraulic Engineering, vol. 126, no. 11, pp. 837-845, 2000. 